\title{
Utopias político-educacionais na formação de professores de História em Barcelona e São Paulo
}

\author{
Political and educational utopias in the training of \\ History teachers in Barcelona and São Paulo
}

\section{Utopías políticas y educativas en la formación de los profesores de Historia en Barcelona y São Paulo}

\author{
Caroline Pacievitch* \\ Vera Lúcia Sabongi De Rossi**
}

\begin{abstract}
Resumo: Este artigo oferece algumas reflexões sobre a presença de utopias político-educacionais na formação de professores de História. Utopias político-educacionais são compreendidas como projetos de um mundo melhor, realizáveis, baseados em profunda crítica ao presente. As fontes documentais são testemunhos de oito professores de História/Ciencias Sociales da província de Barcelona e do estado de São Paulo, entendidos como documentos-monumentos, mantendo o diálogo com autores como A. Colombo, C. Dubois e C. Boto, entre outros. A abordagem comparativa adotada permite lançar algumas luzes sobre a complexidade das perspectivas pessoais e do caráter ideológico que envolve a formação de professores de História/Ciencias Sociales. Os professores expressam o desejo de ser democráticos e apoiam a democracia no seu sentido substancial, conforme N. Bobbio.

Palavras-chave: Utopias. Responsabilidade docente. Formação de professores de História.
\end{abstract}

\begin{abstract}
This paper presents some thoughts about political and educational utopias on the education of History teachers. Political and educational utopias are comprehended as projects for a better world based on a profound criticism of the present. The sources are testimonials from eight history/social studies teachers from the province of Barcelona and the state of São Paulo, studied as documents-monuments, based in A. Colombo, C. Dubois, C. Boto and others. The comparative analysis allows us to study the complexity of personal and ideological issues on the education of History and Social Sciences teachers. The teachers showed the desire to be democratic and they support democracy in its substantive sense, according to N. Bobbio.
\end{abstract}

Keywords: Utopias. Teachers responsibility. Education of History teachers.

\footnotetext{
*Docente da Universidade Estadual de Campinas. E-mail: <pacievitch@gmail.com>

** Docente da Universidade Estadual de Campinas. E-mail: <veraluciaderossi@gmail.com>
} 
Resumen: Este artículo es una reflexión sobre las utopías políticas y educativas en la formación de los profesores de Historia. Utopías políticas y educativas son comprendidas como proyectos para un mundo mejor basado en una profunda crítica del presente. Las fuentes son testimonios de ocho profesores de Historia/Ciencias Sociales de la provincia de Barcelona y en el estado de São Paulo, estudiadas como documentos-monumentos, dialogando con estudiosos como A. Colombo, C. Dubois, C. Boto y otros. El análisis comparativo nos permite estudiar la complejidad de las cuestiones personales e ideológicas en la educación de los profesores de Historia y Ciencias Sociales. Los profesores mostraron el deseo de ser democráticos y que apoyan la democracia en su sentido sustantivo, según N. Bobbio.

Palabras clave: Utopías. Responsabilidad de los profesores. La educación de los profesores de Historia.

\section{Introdução}

Organismos internacionais como a Unesco sinalizam para tendências que se refletem nas agendas educativas de muitos países (por exemplo, o relatório Delors, de 1998). Democracia, tolerância, paz, tecnologia e sustentabilidade são valorizadas como ideais que deveriam penetrar no cotidiano das pessoas. Em muitos casos, propõe-se que isso ocorra a partir dos bancos escolares. Assim, criam-se altas expectativas sobre o poder da educação e, consequentemente, do trabalho dos professores.

Este artigo realiza algumas reflexões sobre a presença de utopias político-educacionais na formação de professores de História. Inicia com uma discussão teórico-metodológica sobre o tema, cotejada com alguns discursos não acadêmicos que afirmam o valor do trabalho docente para alcançar mudanças sociais. Segue-se a análise de testemunhos de oito professores de História/Ciencias Sociales da província de Barcelona e do estado de São Paulo ${ }^{1}$, fontes documentais que permitem a interlocução com a formação docente. A abordagem comparativa adotada permite lançar algumas luzes sobre a complexidade das perspectivas pessoais e do caráter ideológico que envolve a formação de professores de História/Ciencias Sociales.

A abordagem comparativa dos testemunhos de professores da província de Barcelona ${ }^{2}$ e do estado de São Paulo ${ }^{3}$ foi escolhida por seu potencial explicativo

\footnotetext{
${ }^{1} \mathrm{O}$ estudo aqui apresentado é um recorte da tese de doutorado defendida na Faculdade de Educação da Unicamp. A pesquisa contou com financiamento da Bolsa Demanda Social Capes (2010-2012) e com a Bolsa de Estágio de Doutorado no Exterior Capes/Fundación Carolina (2010-2011). Parte dos estudos foi realizada na Universidade Autônoma de Barcelona, sob tutoria do professor doutor Joan Pagès i Blanch.

${ }^{2}$ Referência à província de Barcelona, e não apenas à cidade homônima, capital da Comunidade Autônoma da Catalunha. Os professores entrevistados residem nas cidades de Granollers e de Cerdanyola del Vallès. ${ }^{3}$ Referência ao estado de São Paulo, e não apenas a sua capital homônima. Hortolândia, São José dos Campos
e Campinas são as cidades em que trabalham os professores entrevistados.
} 
para estabelecer diferentes relações espaço-temporais sobre um mesmo tema ${ }^{4}$ (PEREYRA, 1990). Não se trata de realizar "educação comparada" em seu sentido restrito, isto é, comparar sistemas educacionais entre países diferentes. $\mathrm{O}$ que se faz, conforme Cabanas (1983), é utilizar estratégias comparativas dentro de um objeto de estudo determinado no campo da Educação. A intenção é permitir que as explicações emerjam das descrições oferecidas pela comparação, cotejadas às perguntas de pesquisa e aos referenciais teórico-metodológicos.

Autores da chamada "Escola de Lecce", baseados criticamente em estudos de Ernst Bloch, procuram rebater interpretações negativas sobre utopia, principalmente no mundo acadêmico. Para Colombo (2009), utopia não é uma invenção avessa à realidade e à história, nem irreal, já que inclui o trabalho pela realização do ideal esperado. Quarta (2009) demonstra as relações férteis entre utopia, história e esperança. Para este pensador, utopias nascem de insatisfação com o presente e, a partir daí, elaboram projetos históricos. Esses projetos, por desejarem um mundo melhor, mais justo, para todos, podem ser entendidos como políticos.

Baczko (1989, p. 29) demonstra as possíveis relações entre utopia, vidência política, radicalismo revolucionário ou expressão reacionária, permitindo estabelecer diálogo entre utopias e política. Chauí (2008, p. 8), por sua vez, admite que "o discurso utópico pode inspirar ações ou uma utopia praticada, que assume o risco da história". Assumir o risco da história significa reconhecer que as utopias podem sofrer modificações. Entretanto, este aspecto não é um problema para os teóricos aqui apresentados, já que não acreditam na utopia como determinante de ações políticas de mudança, e, sim, como elemento sempre presente nesses tipos de iniciativas.

Há também pesquisadores que se dedicaram a compreender, especificamente, utopias educacionais ou pedagógicas. Talvez, por definirem perfis ideais de professor, possam influenciar a formação docente. De acordo com Cambi (1999), construir algo novo tem sido mote da educação desde Rousseau, ao procurar realizar o ideal humanista de mudar o mundo pela via do conhecimento e da razão. Para Dubois (2009), as utopias pedagógicas - notadamente, a partir do Iluminismo - procuram implantar a liberdade de consciência e a uniformização dos espíritos por meio da generalização da instrução uniformizada sob a responsabilidade do Estado. Segundo o autor, pensadores que utilizaram utopias educacionais procuravam relações mecânicas entre a instrução, a igualdade e a

\footnotetext{
${ }^{4}$ Por exemplo, o projeto Youth and History, para a Europa: ANGVIK, M.; VON BORRIES, B. (eds.). Youth and History. A comparative European survey on historical consciousness and political attitudes among adolescents. Hamburg: Körber-Stiftung, 1997. v. A. Há, também, uma iniciativa em desenvolvimento entre países do Mercosul: CERRI, L. F.; MOLAR, J. Jovens diante da história: o nacional e o internacional na América Latina. Práxis Educativa, Ponta Grossa, v. 5, n. 2, p. 161-171, jul./dez. 2010. Disponível em: <http://www. periodicos.uepg.br>. Acesso em: 01 set. 2011.
} 
formação de cidadãos bem adaptados. O maior problema dessas utopias era ignorar a resistência à consecução de seus projetos. De certa forma, Dubois parece concordar com Cambi ao afirmar que as utopias pedagógicas enfrentam a tensão entre emancipação e conformação das jovens mentes. Para Piozzi (2007), os pensamentos utópicos educacionais não se esgotaram na Revolução Francesa ou nos movimentos de esquerda, mas inspiram professores e formuladores de políticas educacionais até hoje.

Portanto, utopias político-educacionais são compreendidas como projetos de um mundo melhor, realizáveis, baseados em profunda crítica ao presente e que se concretizariam, em parte, pelo trabalho docente. Três discursos atuais, escritos por pessoas de diferentes áreas e filiações políticas, ilustram o uso da educação como ferramenta utópica para mudar o mundo e sinalizam para suas implicações na formação de professores de História. O primeiro exemplo é um pequeno comentário escrito por Ozires Silva, um dos fundadores da Embraer, tratando das relações entre inovação e educação para o Brasil do século XXI:

Vivemos momentos desafiantes e urgentes, e somente nossa atitude tornará possível a concretização de um novo amanhã. No ranking das economias globais, a educação se apresenta como um grande diferencial competitivo no mundo global no qual vivemos. O Brasil, infelizmente, não está preparando os jovens brasileiros para ganhar na competição dos cidadãos de outros países. Mudanças e transformações são mais do que necessárias no nosso sistema educacional, o que será condição essencial para garantir nossa existência como nação soberana. Se não nos prepararmos agora, corremos o risco de comprometer a trajetória para um futuro promissor, condenando nosso país a ser uma nação periférica. (SILVA, 2012, s/p, grifo nosso).

Destacam-se elementos que caracterizam a presença de utopia político-educacional, como a reflexão crítica sobre o presente (mundo global), a necessidade de criar projetos para o futuro de caráter político (competitividade do país) e, por fim, a proposta da educação como "condição essencial para garantir nossa existência como nação soberana” (SILVA, 2012, s/p). Apesar de Silva (2012) não tratar da figura do professor, acredita-se que essas palavras impliquem desafios diretos aos docentes.

O segundo exemplo é um artigo publicado no início de 2013, em que a presidenta Dilma Rousseff apresenta alguns dos resultados mais relevantes dos governos do Partido dos Trabalhadores (PT) e expõe os desafios a enfrentar no novo ano. Os investimentos em educação foram escolhidos para concluir o artigo:

Iremos aproveitar a exploração do pré-sal para concentrar recursos na educação, que gera oportunidades para os cidadãos e melhora a qualificação da nossa força de trabalho. 
É a educação a base que irá nos transformar em um país socialmente menos injusto e economicamente mais desenvolvido. Um Brasil socialmente menos desigual, economicamente mais competitivo e mais educado. Um país que possa continuar se orgulhando de oferecer às novas gerações oportunidades de vida cada vez melhores. Um país melhor para todos. (ROUSSEFF, 2013, $\mathrm{s} / \mathrm{p}$, grifo nosso).

Apesar de representarem posições políticas bastante distintas entre si, Dilma Rousseff (2013) e Silva (2012) demonstram confiança no poder da educação. Seus discursos ilustram, igualmente, uma disputa ideológica sobre o papel que as escolas devem desempenhar na formação dos jovens. A "transformação" é consenso, mas para qual direção? Silva enfatiza a competitividade econômica num mundo global, enquanto Rousseff submete-a a justiça social.

O último exemplo ilustra o impacto da presença de utopias político-educacionais na formação de professores de História. Trata-se de uma frase citada por Pagès (2012) no capítulo "Enseñar a enseñar a participar", em que discutia como formar professores para ensinarem os jovens a ser cidadãos justos e politicamente ativos, principalmente nas aulas de História:

¿Qué impacto tiene todo esto en la formación del profesorado? Es dificil saberlo con precisión. Este es un campo sobre el que deberíamos investigar más. [...] En cualquier caso, nuestra opción es intentar que el alumnado que salga de nuestras aulas de formación inicial por lo menos dude de sus ideas sobre la docencia y vea que existe un contenido social y politico capaz. de formar ciudadanos y ciudadanas democráticos a través de la enseñanza de las ciencias sociales y de la educación para la ciudadanía. (PAGÈS, 2012, p. 206).

Pagès mostra-se cauteloso quanto ao impacto que as iniciativas da "educación para la ciudadanía" podem ter sobre a vida fora dos muros da escola. Por outro lado, acredita que não haveria sentido em ensinar conteúdos que não tivessem relação com problemas e desafios reais. Ele conclui seu artigo confirmando

[...] la confianza de la ciudadanía y de los y las docentes en el valor de la escuela y en el poder transformador de sus conocimientos cuando se aplican a la realidad. [...] Sin embargo, con menos pretensiones de las de aquel profesor canadiense que habiendo asumido su rol de formador de ciudadanos del mañana, exclamaba con humor: "¡El futuro de la nación descansa sobre los profesores de historia!" (Jutras y Guay, 2005, p. 126). (PAGÈS, 2012, p. 207). ${ }^{5}$

Desta forma, apesar de negar a total responsabilidade docente sobre o futuro da nação, Pagès reconhece a importância de abrigar um sentimento de esperança sobre o processo formativo dos professores de História. Um estudo

\footnotetext{
${ }^{5}$ O texto citado por Pagès é: JUTRAS, F.; GUAY, L. Chronique d'une transformation annoncée: l'identité professionnelle des professeurs d'histoire et d'éducation à la citoyenneté. In: DUHAMEL. A.; JUTRAS, F. (Dir.). Enseigner et éduquer à la citoyenneté. Quebec: Les Presses de l’Université Laval, 2005. p. 115-132.
} 
específico com base em 64 dissertações, artigos, livros e capítulos de livros sobre formação de professores de História no Brasil dos últimos trinta anos constatou a presença ou a preocupação com utopias político-educacionais em 31 dos documentos. As utopias apareciam tanto na valorização de professores com vivência política e sentido de responsabilidade docente quanto em propostas para a constituição dos currículos dos programas de formação ${ }^{6}$. O tema, portanto, está presente nas discussões acadêmicas e não acadêmicas sobre educação e ensino de História. A seguir, analisam-se as perspectivas de alguns professores de História/Ciencias Sociales, de São Paulo e de Barcelona, a respeito de sua formação profissional e de suas utopias político-educacionais.

\section{Testemunhos de professores de História/Ciencias Sociales de Barcelona e São Paulo}

Tendo em vista os princípios de uma investigação de tipo qualitativo e comparativo, desejava-se cotejar casos específicos com uma realidade diferente, que permitisse levantar interpretações diversificadas sobre o problema. As universidades de São Paulo e de Barcelona são relevantes centros de pesquisa para a formação de professores de História/Ciencias Sociales. A Universidade de São Paulo (USP) e a Universidade Estadual de Campinas (Unicamp) formaram, principalmente nos últimos dez anos, pesquisadores provenientes de diversas regiões do Brasil, que retornaram e tornaram-se referência na área em seus estados de origem. Com a Universidade Autônoma de Barcelona (UAB) e a Universidade de Barcelona (UB), acontece um processo semelhante, porém em relação a pesquisadores da América Latina (notadamente da Argentina, do Brasil, do Chile e da Venezuela e outros). Assim, embora Barcelona e São Paulo não sejam os únicos centros de pesquisa na área de formação de professores de História, esses centros possuem conexões com outras regiões, tornando-se referências na área.

$\mathrm{Na}$ Espanha, em geral, a formação didática e pedagógica é complementar à licenciatura. Os futuros docentes - já graduados em suas respectivas áreas - têm contato com conhecimentos e práticas educacionais em outra etapa da vida acadêmica. Desde 1970 até 2009, esta etapa chamava-se Certificado de Aptitud Pedagógica (CAP), que poderia ter entre 120 e 300 horas de duração. Atualmente, o professor de Enseñanza Secundaria de Ciencias Sociales/Historia, na Província de Barcelona, ao concluir sua carreira específica (com três ou quatro anos de duração), dirige-se a uma Faculdade de Educação e opta pelo Màster de formació del professorat d'educació secundària obligatòria i batxillerat, formació professional i ensenyaments d'idiomes, com duração de dois períodos letivos.

\footnotetext{
${ }^{6}$ Detalhes deste estudo encontram-se no trabalho publicado pela autora no VIII Encontro Nacional Perspectivas do Ensino de História (2012). A análise das teses de doutorado, defendidas em São Paulo e em Barcelona, encontra-se no primeiro capítulo da tese que originou este artigo.
} 
Quem almeja trabalhar como professor de História no Brasil precisa frequentar um curso de licenciatura em História em instituições de Ensino Superior. Trata-se de um curso de graduação que permite o contato com o ofício do historiador e conhecimentos pedagógicos, didáticos e psicológicos. Os principais documentos oficiais que dirigem a organização dos cursos de História no Brasil são as Diretrizes Curriculares Nacionais (DCN) para as licenciaturas e as DCN para a formação de professores?

Os contatos com os professores de Barcelona iniciaram-se em novembro de 2010. Os primeiros profissionais indicados estavam entre os participantes dos grupos de pesquisa da UAB e destacavam-se pelo bom desempenho, mas foram sugeridos professores que não tinham destaque em sua trajetória. Em São Paulo, as entrevistas começaram em meados de 2011. Os profissionais foram indicados por colegas de grupo de pesquisa, por diretores de escolas ou pela Secretaria Municipal de Educação. Procuraram-se docentes de ambos os sexos; com curta, média e longa experiência; de escolas públicas e privadas; com destaque acadêmico e sem destaque acadêmico.

Lola, Josep, Fidelio (professores de Barcelona), Cândido, Regina, Mercedes, Agnês e Ana (professores de São Paulo) são os protagonistas deste artigo ${ }^{8}$. Foram entrevistados (a partir de roteiro semiestruturado) uma ou duas vezes e preencheram formulários informando dados essenciais para constituir um panorama de seus processos formativos. Houve também a observação de aproximadamente cinco aulas, ministradas nas escolas, nas turmas e nos horários estipulados pelos docentes, com a finalidade de mais bem contextualizar seus testemunhos. Foi importante rastrear alguns dos referenciais mais influentes citados pelos participantes nas entrevistas, pois ajudam a contextualizar algumas de suas afirmações e a formar um panorama de sua trajetória intelectual e profissional. Para construir o texto que segue, não houve hierarquização das fontes. Entrevista oral, anotações de diário de campo, questionários fechados - todos os documentos foram igualmente importantes para narrar e compreender os depoimentos dos professores. O quadro a seguir oferece informações sobre os participantes.

\footnotetext{
${ }^{7}$ BRASIL. Conselho Nacional de Educação. Comissão de Educação Superior. Parecer n. 492, de 03/4/2001. Diretrizes Curriculares Nacionais dos cursos de Filosofia, História, Geografia, Serviço Social, Comunicação Social, Ciências Sociais, Letras, Biblioteconomia, Arquivologia e Museologia. Relatoras: Eunice Ribeiro Durham, Silke Weber e Vilma de Mendonça Figueiredo. Diário Oficial da União, Brasília, 9 jul. 2001, Seção 1e, p. 50.

BRASIL. Conselho Nacional de Educação. Conselho Pleno. Resolução n. 1, de 18/02/2002. Diretrizes Curriculares Nacionais para a Formação de Professores de Educação Básica, em nível superior, curso de licenciatura, de graduação plena. Relator: Ulysses de Oliveira Panisset. Diário Oficial da União, Brasília 04 mar. 2002, Seção 1, p. 8.

${ }^{8}$ Pseudônimos escolhidos e/ou autorizados pelos entrevistados.
} 
Quadro 1 - Professores participantes de Barcelona

\begin{tabular}{|c|c|c|c|}
\hline & Lola & Josep & Fidelio \\
\hline Nascimento & 1952 & 1971 & 1951 \\
\hline Formação & $\begin{array}{c}\text { Filosofia i Lletres (Història } \\
\text { Contemporània) } \\
\text { CAP }\end{array}$ & $\begin{array}{c}\text { Historia/ Geografía } \\
C A P\end{array}$ & $\begin{array}{c}\text { Historia/Geografía } \\
C A P\end{array}$ \\
\hline Local e ano & $\begin{array}{c}\text { Universitat Autònoma de } \\
\text { Barcelona, } 1975\end{array}$ & $\begin{array}{l}\text { Universidad de } \\
\text { Valencia, } 1994\end{array}$ & $\begin{array}{l}\text { Universidad de } \\
\text { Barcelona, } 1981\end{array}$ \\
\hline Pós-graduação & $\begin{array}{c}\text { Mestrado e doutorado } \\
\text { em Didáctica de les Ciències } \\
\text { Socials na UAB }\end{array}$ & Não & Não \\
\hline $\begin{array}{l}\text { Tempo de } \\
\text { trabalho }\end{array}$ & 33 anos & 9 anos & 17 anos \\
\hline
\end{tabular}

Fonte: As autoras.

Quadro 2 - Professores participantes de São Paulo

\begin{tabular}{|c|c|c|c|c|c|}
\hline & Cândido & Regina & Mercedes & Agnês & Ana \\
\hline Nascimento & 1985 & 1982 & 1963 & 1966 & 1957 \\
\hline Formação & História & História & $\begin{array}{l}\text { Ciências } \\
\text { Sociais }\end{array}$ & História & $\begin{array}{l}\text { Ciências } \\
\text { Sociais }\end{array}$ \\
\hline Local e ano & $\begin{array}{l}\text { Unicamp, } \\
2007\end{array}$ & $\begin{array}{l}\text { Unicamp, } \\
2004\end{array}$ & Univap, 1998 & $\begin{array}{c}\text { Plínio do } \\
\text { Amaral, } \\
1985\end{array}$ & $\begin{array}{l}\text { Univap, } \\
1983\end{array}$ \\
\hline $\begin{array}{c}\text { Pós- } \\
\text { graduação }\end{array}$ & $\begin{array}{l}\text { Mestrado } \\
\text { em História, } \\
\text { Unicamp, } \\
2010\end{array}$ & $\begin{array}{c}\text { Doutorado } \\
\text { em História, } \\
\text { Unicamp, } \\
\text { em } \\
\text { andamento }\end{array}$ & $\begin{array}{c}\text { Especialização } \\
\text { em Gestão } \\
\text { Educacional, } \\
\text { Instituto } \\
\text { Claretiano, } \\
2007\end{array}$ & $\begin{array}{l}\text { Mestrado } \\
\text { em } \\
\text { Educação, } \\
\text { Unicamp, } \\
2003\end{array}$ & $\begin{array}{l}\text { Especialização em } \\
\text { Psicopedagogia, } \\
\text { Univap, } 1994\end{array}$ \\
\hline $\begin{array}{c}\text { Tempo de } \\
\text { trabalho }\end{array}$ & 4 meses & 4 anos & 13 anos & 16 anos & 25 anos \\
\hline
\end{tabular}

Fonte: As autoras.

Lola, Josep e Fidelio têm em comum a origem humilde de seus pais, em cidades pequenas e na zona rural. Os dois homens estudaram em escola pública, e Lola frequentou escolas cristãs privadas, sempre com bolsa de estudos. Todos transitaram da zona rural para a urbana. Chegar à formação acadêmica em universidades de excelência na província de Barcelona foi uma conquista inédita em suas famílias. 
Regina e Cândido cresceram na zona urbana de cidades do interior de São Paulo. Seus pais são profissionais liberais ou comerciantes e possuem curso superior ou Ensino Médio técnico. Segundo eles, cumpriram uma trajetória comum às crianças de sua geração, com um destaque: gostavam de estudar e tinham boas notas em todas as matérias.

Ana, Mercedes e Agnês nasceram na zona rural de pequenas cidades interioranas - o que aproxima seu perfil dos de Lola e Fidelio. Seus pais tinham pouca escolarização, mas valorizavam a leitura ou a profissão docente (à exceção de Ana). As três estudaram em instituições pequenas, em turmas multisseriadas. Também se deslocaram para zonas urbanas, onde o contato com colegas ou familiares que avançaram nos estudos fez que almejassem níveis educacionais mais altos.

Esses oito professores pertencem a gerações diferentes e possuem carreiras longas, médias e curtas. Todos são formados em História ou Ciências Sociais, em faculdades privadas de pequeno porte, privadas de grande porte e públicas de excelência. Nenhum cursou licenciatura curta e todos fizeram pós-graduação, lato ou estrito senso.

\section{Formação}

A princípio, Lola desejava ser professora de Educação Física, mas as circunstâncias políticas ${ }^{9}$ e a dificuldade de ir estudar em Madrid a impediram. No entanto, já estava claro, para ela, que sua futura profissão estaria ligada à docência. Logo depois da licenciatura em História, cursou o CAP (Curs d'Adaptació Pedagógica) e começou carreira na mesma escola em que trabalha atualmente.

Fidelio também não planejava, a princípio, ser professor, mas optou pela docência em História e Geografia por razões bem simples: necessidade e gosto. Dos três professores de Barcelona, apenas Josep tinha clareza do que pretendia, desde os 14 anos de idade. A escolha pela matéria de História se deveu, principalmente, a um professor dessa disciplina do Bacbillerato. Segundo Josep, ele conseguia explicar o porquê de muitas coisas que aconteciam no país. Por isso, este professor afirma ter por objetivo transmitir um conteúdo histórico que tenha impacto no cotidiano e faça sentido para os alunos. Por algum tempo, depois da Universidade e do CAP, Josep especializou-se em História Contemporânea, mas notou que foi insuficiente para melhorar o ensino. Recentemente, procurou a $\mathrm{UAB}$ para se aperfeiçoar na didática das Ciências Sociais.

\footnotetext{
${ }^{9}$ Para frequentar o curso de Educação Física, Lola deveria filiar-se a um grupo que apoiava a ditadura de Franco. Portanto, foi por motivos políticos, em grande medida, que ela não cursou sua primeira opção.
} 
Lola foi a que mais avançou na carreira acadêmica. Primeiro obteve o diploma de Mestra de Catalá, uma experiência gratificante, por aprender com profundidade sua língua materna e poder ensiná-l $a^{10}$. Mais tarde, no final dos anos 1990, iniciou estudos de pós-graduação e obteve o título de Màster e, depois, de Doctora en Didáctica de les Ciències Socials, como resultado de um intenso questionamento profissional, em busca de legitimar o trabalho inovador que desenvolvia desde o quarto/quinto ano de magistério.

Fidelio não concluiu a pós-graduação, mas realizou vários cursos de formação continuada. Sua postura frente a esses programas, porém, é de cansaço e frustração. Afirma que deixou de frequentá-los por vários motivos - inclusive porque vai se aposentar. Ele se diz cansado de utilizar os horários de descanso para "bacer el tonto" 11 . Entrou na profissão carregado de utopias que o enfrentamento com a escola foi minando aos poucos. $\mathrm{Na}$ entrevista e nas observações das aulas, reforçou a preocupação de que a escola não fosse uma perda de tempo. Ao mesmo tempo, acredita que o nível dos alunos é muito baixo para que o conhecimento traga resultados efetivos.

Josep, entretanto, ainda está explorando as possibilidades oferecidas para conhecer mais sobre a profissão, de três formas: no diálogo com professores mais experientes (principalmente no início da carreira); na intuição, pela "tentativa e erro"; e em contatos esporádicos com a universidade (congressos, encontros, cursos e grupos de estudos e pesquisas).

Estes três professores optaram por carreiras universitárias voltadas para a História (principalmente Lola e Josep) porque acreditavam na possibilidade de transformar o mundo por meio deste conhecimento, que pode interligar passado e presente e, possivelmente, despertar para questões políticas. Eles cursaram o CAP e concordaram que não foi suficiente para que desenvolvessem habilidades didáticas e conhecimentos pedagógicos que permitissem dar aulas da forma como desejavam.

Cândido e Regina, jovens professores, atribuíram significados pessoais e utópicos para a profissão no momento em que a escolheram: queriam algo que fosse intelectualmente estimulante, divertido e socialmente significativo. Situações diferentes, entretanto, ocupavam as mentes de Agnês, Mercedes e Ana: todas procuraram conciliar família, maternidade e profissão. O critério para a escolha dos cursos superiores foi menos a excelência do que a adequação ao horário escolar dos filhos e o custo das mensalidades.

\footnotetext{
${ }^{10}$ Durante a ditadura franquista (1939-1975), a língua catalã fora proibida, e seu uso voltou a ser estimulado a partir do final dos anos 1970. Atualmente, todo professor que trabalha na Catalunha deve comprovar proficiência em catalão.

${ }^{11}$ Todas as citações provêm das transcrições das entrevistas - que foram devidamente autorizadas - ou de documentos preenchidos de próprio punho pelos participantes.
} 
Os cinco professores paulistas foram unânimes em dizer que aprenderam a ser professores com os pares, após o início da vida profissional. Cândido e Regina fazem crítica à dicotomia entre teoria e prática em suas graduações de forma bem mais contundente que Mercedes, Ana e Agnês. Mas todos concordam (inclusive Lola, Josep e Fidelio) que nem as disciplinas da historiografia, nem as educacionais, prepararam adequadamente para enfrentar a realidade escolar. Ana, Mercedes e Agnês não fazem críticas fortes a sua formação inicial, talvez porque não tivessem grandes expectativas sobre o curso superior e por acreditarem que a docência se aprende na prática.

\section{Papel do professor de História/Ciencias Sociales}

Formar alunos melhores (mais críticos, mais tolerantes, menos influenciáveis, para Lola, Josep e Fidelio, respectivamente) é tarefa do professor de História. Porém é preciso ultrapassar um primeiro desafio: motivá-los para o conhecimento. Em sua opinião, se os jovens não percebem o significado de aprender História, fica muito mais difícil conduzir as atividades de ensino. Lola reforça que " $n o$ tienen ganas de trabajar" e, por isso, o professor deve ter muito entusiasmo e paciência.

Os cinco professores de São Paulo interpretam seu trabalho como forma de ajudar os jovens a entendê-lo e a participar de forma autônoma e crítica. Sua definição para a tarefa do professor de História articula o passado ensinado aos desafios do presente (as necessidades/potenciais dos alunos, a crise dos valores, o sucesso escolar, a preservação da democracia), pensando nas vivências futuras dos jovens.

Ser professor, para Fidelio, não foi “cuestión de vocación". Porém, com os estudos no magistério, acabou por encantar-se com o tema do ensino e adicionou esse encanto a uma motivação utópica. Por isso, a princípio, projetava sua vida profissional de modo bem diferente da realidade que enfrentaria futuramente. $\mathrm{Na}$ entrevista, respondeu à pergunta sobre sua utopia inicial dizendo que acreditava em transformar a sociedade a partir do ensino. Josep também passou por desencanto com a profissão. O profissional que desejava ser no começo da carreira já não é mais seu objetivo principal. Mudou a procura do equilíbrio entre o ideal de professor e as possibilidades oferecidas pelos seus alunos:

Evidentemente cada uno tiene en la mente, cuando quiere ser profesor, un ideal. [...] pero en sentido de poder cambiar, de hacer cambiar a las personas, a los alumnos y tal, eso es un modelo, es una idea que tú tienes de lo que debe ser el buen profesor. Pero creo que se ha modificado cada año de mi experiencia profesional. 
Regina e Cândido avaliam o potencial de sua ação a partir da ampliação do nível de conhecimento histórico dos alunos. Portanto, o mais importante não é tanto sua influência pessoal, mas a eficiência com que ensinam História - o que parece concordar com a posição de Josep. Agnês e Mercedes, porém, acreditam que o papel do professor vai além do conteúdo, pois passa pela formação de valores e atitude crítica. Diz Agnês: "Porque en acho que o trabalho de professor é ir um pouco mais além do que não é só o conteúdo, é muito mais que isso. Questão da formação, valores".

Lola, desde muito jovem, desejava transformar o mundo, e, conforme seu testemunho, as dificuldades atravessadas na escola não a forçaram a desistir. Talvez a formação continuada tenha fortalecido sua esperança no potencial transformador da educação. Ana conduziu diretamente sua resposta para a política e para o problema de ser criticada por ensinar História da forma como faz. Em seu modo de ver, o papel do professor de História é "desmistificar os mitos que a gente fa\%. [...] Eu vejo que o professor de História tem essa responsabilidade grande, que é despertar a politica".

Independentemente das frustrações e do cansaço, Fidelio parece sentir-se muito à vontade na escola e no contato com os alunos: "La faena esa me gusta, la verdad. No tengo porque cambiar [...]". Em suas aulas, apesar de utilizar poucos recursos, Fidelio é atencioso, aproveita bem o tempo e faz o que pode para que aprendam. Os sentimentos de desistência ou frustração estão invisíveis para os alunos. No entanto, ele não recomendaria para ninguém, hoje, ser professor. Em sua opinião, lutar contra o poder da mídia torna ingrato o trabalho. Lola diz que continua sendo professora porque gosta e porque traz sentido a sua vida.

Mercedes, Ana, Cândido, Agnês e Regina não hesitam em estipular o papel do professor de História e, diferentemente de Fidelio, não duvidam da validade do que almejam. Entretanto, quando perguntei como projetavam o tipo de professor que seriam, algumas inseguranças apareceram de modo explícito - parece que menos em Ana.

Para Regina e Cândido, as inseguranças foram ainda maiores, e o sentimento de despreparo, também. Regina disse: "Projetava que eu ia ser uma professora muito democrática. Muito democrática". Cândido também: "O que eu imaginava que eu não seria e eu acabo sendo algumas vezes é ter que ficar impondo muitos limites e chamando muito a atenção". Ambos precisaram rever o significado de ser democrático quando tiveram que ganhar a atenção de ruidosos grupos de adolescentes que não encontravam sentido na escola. Como disse Lola, era preciso entrar em sala com muito entusiasmo ${ }^{12}$.

\footnotetext{
${ }^{12}$ Funes; Gingins e Moreno (2000, p. 138) estudaram justamente a tensão vivida pelos docentes de Ciências Sociais, mostrando que era uma das ilusões da profissão; afinal, todo docente exerce autoridade.
} 


\section{Responsabilidade docente}

As utopias, segundo Quarta (2009) e Colombo (2009), consistem em projetos de futuro eivados de esperança, baseados em visões críticas sobre o presente. Portanto, é válido prestar atenção ao fato de todos os professores afirmarem que continuarão sendo professores. Nenhum se arrepende da escolha, nem mesmo os que enfrentam realidades mais duras, em contraste com Fidelio. O desejo de continuar vem de uma interpretação crítica da realidade, unida ao gosto, desdobrando-se em iniciativas de melhoria.

Os professores mais jovens (como Josep, para o caso da província de Barcelona) acham difícil mapear as mudanças que acontecem em seus alunos, pelo pouco tempo de convivência. Regina, Lola, Agnês e Mercedes compartilham da serenidade ao dizer que nem todos os alunos aproveitariam da mesma forma as oportunidades, mas que se sentiam na obrigação de lhes oferecer condições para tanto. Ana, Cândido, Fidelio e Josep lembram que, em alguns casos, os alunos só percebem a influência do conhecimento histórico muito tempo depois ter saído da escola. Uma coincidência nas narrativas dos professores sobre o impacto de seu trabalho foi a metáfora da semeadura, que esteve clara em Mercedes e Regina, mas apareceu também em Cândido: "Porque tem coisas que às vežes é alguma coisa que você diə, ou um texto que vocêpassa, um filme que você passa, que aquilo muda a maneira de ele ver algumas coisas, mas não é tão direto, né?'.

Parece que o desejo de continuar na carreira tem relação com o reconhecimento do potencial de interferência no futuro. Com esta pergunta, pretendia-se detectar sinais das utopias políticas e educacionais na vivência concreta dos docentes com a profissão. Talvez seja interessante começar pelo mais cético, Fidelio. Quando falou do futuro, tratou dos sentidos de ser professor de História/ Ciencias Sociales e do poder de impacto de suas aulas sobre a vida dos alunos. Ele é pessimista quanto ao alcance de sua ação educativa sobre os alunos, pelo menos na escola pública. Entre a esperança e a frustração encontra-se Josep. Ele não está certo quanto ao impacto de suas aulas. Certo sentimento de compromisso profissional acompanha sua prática e, mesmo que seja difícil mapear os avanços em sua trajetória e na vida dos alunos, ele busca continuamente a melhora. Para ele, a relação entre política e docência encontra-se no equilíbrio entre aquilo que acredita que deve fazer e o que pode, efetivamente, realizar.

$\mathrm{Na}$ observação de suas aulas, notaram-se tentativas de fazer que os alunos compreendessem a importância da disciplina. Parecia que Josep procurava conjugar as utopias políticas gerais com as tarefas possíveis de concretizar na escola. Seria o reconhecimento dos limites dos professores, dos alunos ou do sistema como um todo? Aparece em seu testemunho o desejo de que o conhecimento que transmite na escola contribua para que os alunos transformem suas vidas. 
Josep não deixou de acreditar que história e política estão relacionadas, apesar de haver abandonado atividades políticas e partidárias após o ingresso na carreira docente. Renunciar essa ligação seria uma "neutralidad demasiado hipócrita". É na forma de apresentar as aulas, muito mais que no conteúdo, segundo suas próprias palavras, que essa relação política se estabelece. Para ele, há uma possibilidade, aberta, quase incontornável, de que seu trabalho modifique o futuro e influencie o comportamento dos jovens, já que transmite um passado comum para gerações passadas, presentes e vindouras. Porém reconhece que é impossível saber até que ponto essa influência vai.

É grande a diferença entre o que desejava no início da carreira e o que acredita que pode fazer hoje, e, por isso, seu grau de esperança, elemento forte da utopia, é menor que o de Lola. Josep afirma que sua participação política diminuiu porque "quizáas soy más consciente del pequeñisimo papel que puedo tener en la sociedad", o que não supõe um desinvestimento na qualidade de suas aulas. Aliás, seguir melhorando a prática pedagógica é o único plano de futuro que elencou.

Lola, entretanto, não duvida do impacto de seu trabalho sobre o futuro dos jovens. Para ela, é possível que, a partir de sua prática, os alunos mudem suas visões: "Estoy convencida. No con todos, ¿eh?, no con todos, eso ya sería, tendría que ser divina". Ela tem clareza de que não consegue garantir a aprendizagem de toda a classe, mas isso não retira a segurança de que seu trabalho é importante.

$\mathrm{Na}$ interpretação de Lola, ser professor é assumir um compromisso com o futuro de todos, carregado de profissionalismo e de afeto. A concepção de professor como intelectual transformador - influência de Henry Giroux e Paulo Freire (autores citados como favoritos pela docente) - conjuga-se com a afetividade dirigida aos alunos, conforme Max van Manen. Lola entende isso como vocação, sem ingenuidade, mas com afeto e mobilização:

Si quiero ser una buena profesional de las ciencias sociales, yo creo que bay algo de vocacional en eso. Mi modo de estar en el mundo es siendo profesora de historia. Es mi manera de actuar en el mundo. [...] Es este espiritu, como de contradicción, yo me voy a rebelar, yo creo que es algo también que ba sido como muy natural.

Fidelio não comunga desse sentimento. Ele entende que é pouco provável que as aulas de História sirvam para alguma coisa. Quando muito, alguns jovens guardarão lembranças positivas ou carinhosas das aulas de História/Ciencias Sociales. "¿Poder? Ninguno. \{risos\} [...] Quizás un buen recuerdo. [...] Quien tiene poder son los medios de [comunicación de] masa, pero nosotros. Creo que no, zeh?". Talvez por isso, diz que, se pudesse começar de novo, não seria professor, pois não compensa o esforço. A renúncia é acompanhada pela frustração, e a procura por responsáveis não exclui a si próprio: 
[...] si tenemos unos porcentajes de Insuficientes de un 30\% a un 35\%, es difícil estar satisfecho con tu trabajo. ¿Culpa tuya? Una parte. ¿Culpa de las familias? Otra parte. ¿Culpa del ambiente? Otra parte. Yo creo que todos podemos aqui hablar, hablar, no buscando culpables sino buscar una manera de que eso se solucione. Porque vamos mal. Es frustrante para ellos, mucho ieb? Es frustrante para nosotros, para las familias cuando ves estos resultados.

Para ele, falham aspectos humanos e afetivos, e não poupa críticas à falta de didática de seus colegas na Secundaria. Apesar de dizer que não pode fazer nada a respeito, notei em suas aulas sinais de resistência: o toque nos ombros e nos cabelos dos alunos, o diálogo amistoso, as piadas e os risos, as explicações simples e claras, as ajudas individuais.

Para Josep, o conhecimento histórico deve ser vivo, fazer sentido na vida dos alunos: "Que esté vivo significa que lo que ellos van a aprender les sirva en su vida personal y en su entorno, en su propia historia". As raízes para esse tipo de posição sobre seu papel político e profissional, segundo o próprio Josep, podem advir das leituras em história social e marxismo que cultiva desde os 15 anos. Trata-se de uma forma de compreender o papel da ciência da História para a transformação da sociedade. Aliás, quem deve realizá-la são os alunos. Ao professor, cabe a transmissão - em formatos atraentes e participativos -, que é o momento em que sua posição política manifesta-se sem doutrinar. Ele interpreta a responsabilidade do professor de História como ensino de conteúdos de forma democrática, participativa, em que os alunos estejam "implicados".

Essa mesma característica nota-se entre os professores paulistas. Mercedes, Ana e Regina fizeram referências mais diretas ao modelo de trabalho desenvolvido por elas, que, junto com o conteúdo, seria capaz de mudar a visão dos jovens, pelo menos em alguns aspectos. Um contraste importante está nas repostas de Mercedes e Agnês. Para esta, a "escola não redime". Para aquela, se não houver mudança, o processo de ensino fracassou, e é papel da escola oferecer condições dignas para que os professores consigam cumprir os objetivos assumidos pela Educação, que, com Cambi (1999), entende-se como emancipadores. Ana compartilhou do ceticismo sobre o potencial transformador da educação, pois gostaria de deixar a escola para "realmente trabalhar a promoção, não a permanência dele [do aluno] naquela miséria”. Do contexto dessas respostas, infere-se que o perpetuador da miséria não é a educação em si - pois todos confiam no valor do conhecimento histórico -, mas o sistema escolar. Há ecos dessa posição nos termos que Agnês usou para caracterizar seus alunos de EJA: foram excluídos ou expulsos da escola. Não são desistentes nem fracassados.

Diferentemente do contraste que existe entre Lola, de um lado, e Josep e Fidelio, de outro, não há grande distanciamento entre os participantes do estado 
de São Paulo quanto à crença no potencial transformador do professor de História. Existe um consenso de que, pelo menos em termos cognitivos, é inaceitável que alunos terminem o ano letivo da mesma forma que começaram. Porém esta afirmação pode ser nuançada. Primeiro, porque eles não são "onipotentes", isto é, sabem que o êxito não aparecerá em todas as aulas de todas as turmas. Segundo, como bem lembram Mercedes, Ana, Agnês, Regina e Cândido, parece não ser da natureza do sistema escolar promover a emancipação de todos, embora seja o mote da Educação, explícito no perfil profissional dos PPPs das cinco escolas do estado de São Paulo.

\section{Utopias político-educacionais}

O último ponto abordado nas entrevistas foram as utopias e/ou sonhos declarados pelos participantes. Lola recorda que seu pai reservou, para ela, um lugar na casa em que pudesse ter sua mesa de estudos e uma pequena biblioteca. $\mathrm{Na}$ parede desse pequeno quarto, ela confeccionou um pôster, com recortes de jornais, mostrando a sociedade dividida entre ricos e pobres. Afirmou que o desaparecimento das injustiças sociais teria sido, talvez, sua primeira utopia - a que carrega até hoje, nessa etapa de tranquilidade, para aperfeiçoar e divulgar seu trabalho:

Si al final de curso te das cuenta que la cosa ha ido bien y que los muchachos han aprendido y que además el clima que se ha producido alrededor de aquello que tú habías seleccionado es un clima propicio no solo para el aprendizaje de la historia, sino también para el interés en los temas históricos, en los temas de vida política, etc., etc. pues, estás satisfecho y eso te da más razones para seguir.

E continua, não somente na escola, mas em todos os âmbitos de sua vida: "Incluso te diría cuando en la vida privada, o paralela [...] tú te comprometes con una asociación ciudadana o con un grupo que está trabajando en algo, de hecho estás haciendo como una labor paralela a la de profesor". Quando Josep falou em idealismo, apresentou-se o momento perfeito para perguntar qual seria seu sonho ou sua maior esperança, em qualquer âmbito da vida. Diferentemente dos outros professores, ele optou por uma resposta abrangente, fora da área educacional:

[...] para mí, personalmente, yo creo que yo busco, es muy importante para mí mucho más tolerancia. La idea de transformar y de cambiar la sociedad creo que pasa un poco más por el ser mucho más tolerantes las personas, entre nosotros. Mucho más tolerante en una convivencia que ahora es mucho más multicultural. [...] El conocimiento histórico aqui puede aportar algo, a que las personas pueden ser mucho más tolerantes, mucho más respetuosas, mucho más empáticas, no sé, convertir en un mundo mucho más justo, más igual. 
Ele concordou que essas ideias se relacionam com sua experiência na aula d'acollida ${ }^{13}$, mas reforçou que é parte de sua crença como cidadão. Aprender a viver com os outros é fundamental. Josep, abraçando essas obrigações como responsabilidade profissional, encontrou-se com uma realidade escolar que limita sua concretização em grande medida. Compreende-se, daí, a dificuldade em atribuir algum poder ao ensino de História.

Para Fidelio, a experiência acumulada comprovou que sua esperança não poderia ser realizada. Ele explicou que sua utopia relaciona-se com a influência da mídia sobre as mentes dos jovens e dos adultos. Em sua opinião, as pessoas não devem seguir passivamente a programação estipulada; elas precisam selecionar informações. Isso aconteceria com o trabalho organizado e "activo" nas escolas e com a colaboração direta dos pais - estes, também, instruídos a partir das "escolas de pais".

O professor reconheceu, principalmente ao final da entrevista, a desvalorização da instrução e do conhecimento. Para Fidelio, é o ponto em que a escola deveria repensar-se, mas ainda não existe solução. Ele é cético se, em algum momento, essa solução aparecerá. Talvez por isso utilize a palavra renúncia, como no trecho:

Actualmente, ¿lo conservo esto? Si que lo conservo, pero así como antes pasaba muchísimas, muchisimas horas preparando, haciendo fichas, preparando los documentos, audios, ahora no lo hago. Porque no puedo. [...] La televisión es superior. Tiene más incidencia. En otros tiempos las familias tenían una implicación mucho más activa y posición en eso, aquí mismo. He renunciado a eso. Porque me veo incapaz. Incompetente. [...]

[pesquisadora]: Has dicho que una parte de esas utopias, aquellas de principio... Renuncié...

Mesmo assim, quando questionado sobre seu maior sonho/esperança/ utopia, em qualquer âmbito da vida, ele escolheu citar um desejo do campo educacional: "El principal seguro que es esto. Que la escuela, que la enseñanza sirviese de algo. No de ser puros loros". Esse ponto merece destaque, principalmente na comparação entre as intenções dos três professores de Barcelona.

Utopias educacionais que exigem mais do que o professor pode realizar causam um choque demasiadamente difícil de superar quando a realidade mostra suas barreiras. Em Lola, entretanto, pode-se interpretar que são as utopias educacionais e políticas que ajudam a atribuir sentido a seu trabalho:

\footnotetext{
${ }_{13}^{13}$ Os alunos estrangeiros frequentam as "salas de acolhida", nas escolas públicas catalãs, pelo tempo que for necessário, durante o horário de aulas normal. Nessas turmas, entram em contato com a cultura catalã - principalmente com a língua - e aprendem sobre os novos hábitos que o sistema escolar lhes exige.
} 
Que sirva para algo, que sirva para algo \{risos\}. Es decir, que ese camino que yo creo que emprendemos todos de algún modo de mejora personal, pero también, de mejora de tu entorno, etc., que eso se produzca. La verdad es que en esos momentos no hay muchos motivos para la esperanza, pero soy bastante incombustible.

Não se deixar deprimir pelas dificuldades - ser incombustível; não se conformar com o estabelecido e procurar fazer as coisas da maneira que lhe parece melhor - ser insubmissa; trabalhar diretamente com as necessidades dos alunos - abrir janelas. Lola narrou sua trajetória profissional como intuitiva e "insubmissa" desde o começo. Ela conserva o desejo de que, um dia, a justiça social esteja presente no mundo todo. Mas essa projeção se concretiza em ações distintas, dentro e fora da escola: trabalho em ONGs de caráter educacional e assistencial; desenvolvimento de projetos alternativos de ensino (sobre os temas da educação para a paz, valores, ética, justiça, etc.); produção de material didático (livros didáticos); participação em grupos de discussão; incentivo à criação de ONG entre ex-alunos.

Sua prática ganha mais significado na proximidade afetiva e intelectual com os alunos e o desejo de trabalhar por um mundo melhor. Não é a militância política que exige que seja boa professora, mas a docência é que permite acreditar nas utopias. Josep e Fidelio sentem que seu trabalho pode ter algum impacto no futuro, mas não sabem como controlá-lo. Também têm dúvidas se os alunos, no futuro, efetivamente terão uma vida melhor. Porém a frustração com as utopias não implicou desistência. Os três professores concordaram com o papel transformador do docente de História: estímulo ao pensamento dos alunos, preparo das aulas, uso de materiais inovadores e, principalmente, promoção de debate e questionamento. Isso vem ao encontro do referencial teórico-metodológico ligado ao marxismo não ortodoxo (notadamente, na influência das pedagogias críticas) presente nos testemunhos dos docentes ${ }^{14}$.

Cândido, Regina, Mercedes e Ana disseram que sua utopia é ver um mundo mais justo: "para todos, com qualidade, com dignidade", "que não tenha tão poucos com tanto e tantos com quase nadd", "contribuir para que a desigualdade social diminua", "que o mundo seja menos intolerante". Parece que entre esses professores o sentido de transformação social aparece com maior intensidade do que entre Lola, Josep e Fidelio. Aliás, nota-se conexão entre Cândido e Josep no quesito "tolerância". Ambos se preocupam com a forma como certos alunos - imigrantes, homossexuais, negros - são tratados por professores e colegas. Mesmo assim, nenhum dos participantes falou de revolução, instauração do socialismo ou desaparecimento das desigualdades. Parece que predomina uma ideia difusa sobre justiça social como aproximação entre as classes, e não, necessariamente, sua abolição. Por isso, o

\footnotetext{
${ }^{14} \mathrm{~A}$ recorrência à pedagogia crítica transparece também em teses de doutorado sobre formação de professores de História, aspecto estudado na primeira parte da tese que inspira este artigo.
} 
teor dessas utopias políticas, quiçá, aproxima-se de concepções de democracia que se identificam com a dita "democracia formal" como ponto de partida para a justiça social e a igualdade (BOBBIO; MATEUCCI; PASQUINO, 1998, p. 326).

É Regina quem ajuda a conectar as utopias políticas com as educacionais, por dizer que a luta contra as desigualdades faz parte do trabalho de ensinar História. Sua utopia educacional (contribuir para que o aluno consiga ter um pensamento autônomo) é parecida com as de Mercedes (uma escola que permita que todos aprendam, e aprendam bem) e de Agnês (fazer um trabalho significativo para os alunos), pois as três focalizam-nas no sucesso dos alunos e procuram equilíbrio entre autoridade, democracia e respeito ao potencial de jovens. Regina amplia, com Cândido, o sonho de tornarem-se professores melhores. Assim, se os alunos sentirem prazer na escola e atribuírem sentido aos estudos, aprenderão melhor e, por consequência, serão pessoas autônomas, tolerantes e politizadas, que contribuirão num grau mais elevado para a transformação política e social que projetam.

Antes disso, porém, acrescente-se outro ingrediente das utopias: a crítica ao presente (COLOMBO, 2009; QUARTA, 2009; DUBOIS, 2009). Mercedes, Cândido e Regina ressaltaram suas condições de trabalho. As utopias existem, são importantes para manter o entusiasmo, mas não desmobilizam os professores, nem os responsabilizam individualmente, como temem Shiroma e Evangelista (2004). Eles estão cientes de que não precisam (nem podem) concretizar todas as modificações almejadas. Em seus discursos, a escola não é a ferramenta utópica para regeneração e emancipação da sociedade, como queriam os iluministas (BOTO, 2003; PIOZZI, 2007). Nem eles se identificam como agentes políticos por excelência, como enunciou Rousseau, segundo Cambi (1999) e Furter (1974). Talvez se aproximem da ideia de professor como intelectual transformador, que Giroux (1997) empresta do conceito de intelectual orgânico de Antonio Gramsci (SOARES, 2004), mas, em seus testemunhos, aparece a crítica às condições materiais que deveriam garantir a dignidade do trabalho docente. Este ponto também parece ser mais explícito entre os professores do estado de São Paulo que entre os da província de Barcelona.

As utopias político-educacionais constituem-se com o rigor aprendido nos processos de formação institucional (inicial e continuado) e procuram unir-se ao enfrentamento cotidiano de condições de trabalho que tornam quase impossível que executem o "papel do professor de História" conforme projetaram nas entrevistas. Entretanto, parece que as utopias são importantes para constituir a profissionalidade do professor. 


\section{Considerações finais}

Algumas escolas ofereceram, no PPP (São Paulo) ou no Proyecto Educativo de Centro (Barcelona), um diagnóstico realista das condições de seus alunos e, principalmente no caso do estado de São Paulo, acrescentam ao perfil do professor atividades de formação continuada que os ajudem a alcançar as metas. As habilidades desejadas por escolas da província de Barcelona e paulistas coincidem: os professores precisam ser democráticos, atenciosos, tolerantes, esforçados e atualizados a demandas como meio ambiente, inovação tecnológica e educação para a paz, o que demonstra a chamada "coincidencia temporal das agendas educativas" 15 nos sistemas de educação em tempos de globalização (CANÁRIO, 2006, p. 30). Quando os próprios participantes projetam ser professores democráticos, que utilizam as mídias ${ }^{16}$ e causam impacto no futuro dos alunos, correspondem ao que, oficialmente, as escolas esperam deles. Certamente, não criaram essas perspectivas apenas quando leram os documentos escolares.

Talvez a distinção entre democracia formal e democracia substancial seja mais adequada para ajudar a compreender o desejo de serem professores democráticos e apoiarem a democracia. Para Bobbio; Mateucci e Pasquino (1998), a democracia formal inclui apenas métodos ou "comportamentos" que um Estado assume no jogo político, como: a representatividade ou a eleição direta, o sufrágio universal, o voto livre, o princípio da maioria numérica, etc. Como se sabe, um Estado pode apresentar esses aspectos e, ao mesmo tempo, não praticá-los. Porém a democracia substancial não leva em conta apenas os métodos:

[ela] faz referência prevalentemente a certos conteúdos inspirados em ideais característicos da tradição do pensamento democrático, com relevo para o igualitarismo. Segundo uma velha fórmula que considera a Democracia como Governo do povo para o povo, a democracia formal é mais um Governo do povo; a substancial é mais um Governo para o povo (BOBBIO; MATEUCCI; PASQUINO, 1998, p. 328).

Para os mesmos autores, é na teoria de Rousseau que ambas as perspectivas se fundem: "[...] a Democracia perfeita - que até agora não foi realizada em nenhuma parte do mundo, sendo utópica, portanto - deveria ser simultaneamente formal e substancial" (BOBBIO; MATEUCCI; PASQUINO, 1998, p. 328). Nesse sentido, a defesa de elementos inerentes à democracia substancial compõe as utopias político-educacionais propostas pelos entrevistados.

\footnotetext{
${ }^{15}$ Expressão usada por Rui Canário, emprestada de Ronald Sultana na obra: SULTANA, R. Education et formation de qualité pour l'Europe de demain. In: LAWN, M.; NÓVOA, A. (coords.). L'Europe réinventée : Regards critiques sur l'espace européen de l'éducation. Paris: L’Harmattan, 2005. p. 163-195.

${ }^{16}$ É interessante notar a relação entre o uso das mídias e o combate a elas (um dos objetivos mais citados nas entrevistas) e os pilares das utopias político-educacionais entre os iluministas, conforme Piozzi (2007, p. 721): "[...] dando primazia à informação e demonstração racional e científica, aptas a instrumentar o aluno na análise dos fatos e a decodificar os engodos do discurso arquitetado para seduzir o coração e submeter a vontade".
} 
Porém as frustrações aconteceram quando depararam com alunos que não combinavam com os modelos que esperavam. Como democráticos, não poderiam impor seu modelo de vida. Mesmo assim, mantiveram a intenção de que os jovens sofressem algum tipo de mudança ao longo do período em que fossem seus alunos. Os professores que demonstraram maior tranquilidade em avaliar este objetivo foram aqueles que centralizaram a atenção no desenvolvimento da compreensão do conhecimento histórico, como Regina, Lola e Mercedes. Elas esperavam que os alunos, em primeiro lugar, aprendessem História - e, em certa medida, que possuíssem condições de trabalho para tanto. Isso não significava que não se preocupavam com a transmissão de valores ou com a politização dos jovens, mas, quiçá, estavam menos aflitas quanto aos limites de seu trabalho frente à transformação social e aos meios com os quais competiam. Mercedes sintetizou essa ideia quando disse que passou de uma professora "borizontal" para uma "vertical', isto é, daquela que desejava massificar seu ponto de vista àquela atenta às diferenças e aos potenciais dos alunos.

Parece que é um tema importante a confiança (ou falta dela) sobre o impacto das aulas de História entre os jovens. Os oito professores participantes, cada um a seu modo, atribuem importância aos valores humanistas, à democracia e à cidadania - principalmente na compreensão da Política. Como antecipado no artigo de Marilena Chaú, princípios humanistas são importantes para a construção das utopias na modernidade e ajudam a forjar ideias caras aos professores entrevistados. Diz a filósofa:

O humanismo exalta a razão humana, a lógica e a experiência no plano do conhecimento, e a vontade no plano da ação, isto é, o poder para dominar, controlar e governar os apetites e as paixões. O homem é, pois, capaz de guiar-se a si mesmo, desde que, por meio da razão e da vontade, estabeleça normas de conduta e códigos para todos os aspectos da vida prática (CHAUí, 2008, p. 9).

Pesquisas como as de Guimerà (1991) e Fonseca (1996), entre outros, ajudam a constatar uma generalidade entre os docentes de História: o posicionamento político à esquerda, com tendência progressista ou, às vezes, libertária. $\mathrm{O}$ que chama atenção é que, ao contrário da imagem recorrente no senso comum sobre o professor de História, os participantes não são revolucionários - nem reacionários. Existem, sim, críticas à mídia e preocupação com valores. Os que possuem filiação partidária não militam. A participação sindical é ausência marcante, pois seria o órgão mais próximo para lutar pelas condições de trabalho. Por outro lado, existe uma série de indícios de outros significados para a participação política, na forma de mobilizações em diferentes âmbitos da sociedade, como, por exemplo, em ONGs de alcance local e internacional, em atividades das igrejas Católica ou Adventista, no movimento feminista e em ações de cunho cultural (como os cineclubes). 
Quando Almeida Neto (2002) analisou este ponto, verificou entre seus entrevistados (também professores de História) a ausência de militância política própria e o desejo de que seus alunos se mobilizassem. Soares (2008), porém, alerta para o perigo de confundir clareza política com ativismo em sala de aula. Parece que os oito participantes da presente pesquisa evitavam confundir sua profissão com proselitismo (político ou religioso). Ao atribuírem maior importância ao conhecimento histórico (junto com a formação de valores humanistas e laicos), tentavam escapar da armadilha de impor aos alunos a responsabilidade pela mudança do mundo. Obviamente, eles esperam que os jovens de hoje tenham uma vida melhor do que as gerações passadas. Porém não se pode afirmar, com base em seus testemunhos, que com isso abdicam da própria responsabilidade pela mudança e, principalmente, dos deveres da profissão.

Um último ingrediente vem dos autores influentes. Combinando com a posição política declarada, mencionaram autores voltados, politicamente, à esquerda: historiadores marxistas como Josep Fontana, Edward Thompson e Eric Hobsbawm; o próprio Karl Marx e Mikhail Bakhtin; e, na educação, Paulo Freire e Henry Giroux. Mas a lista não acaba aí: Weber, Deleuze, de Certeau, Max van Manen, Marc Bloch, Jacques Le Goff e a Bíblia, entre outros, são também importantes para os docentes. Existe, entretanto, alguma dificuldade para introduzir - e vivenciar - esses referenciais no planejamento escolar. Entre os professores do estado de São Paulo, conforme avançam as gerações, há um caminhar de autores modernos para pós-modernos e de marxistas ortodoxos para não ortodoxos.

Talvez um dos sentidos mais importantes a emergir desses testemunhos, junto com a crítica à dicotomia entre historiografia e didática, seja a ausência de menções a autores que embasam o entendimento de educação e ensino de História - mesmo entre docentes que realizaram pesquisas e formaram-se recentemente (a exceção é Lola). Inexistem citações a investigadores da Didática da História, como Pilar Benejam, Joan Pagès, Joaquim Prats, Ernesta Zamboni, Kátia Abud ou Maria Carolina Galzerani. Seria um sinal do pequeno impacto da Didática da História sobre a formação dos professores ou da ainda minguada divulgação de seus trabalhos nos cursos de licenciatura?

Para aprender a ser professor, portanto, buscaram outros caminhos: o diálogo com os mais experientes, a tradição, a sucessão de experiências do tipo "tentativa e erro". As leituras do tempo da formação inicial ainda constituem balizas importantes, mas são revistas e criticadas conforme avançam na compreensão da docência.

Defensores da democracia, sensíveis às diferenças e aos valores humanistas, com postura política de esquerda, relativamente seguros de seus conhecimentos 
historiográficos e inseguros de seus conhecimentos didáticos: esses são alguns dos sentidos emergentes dos oito testemunhos, que forjam uma possibilidade de caracterização. É interessante adicionar como eles explicam o papel do professor de História hoje. Segundo Regina, Lola, Cândido, Josep, Agnês, Fidelio, Ana e Mercedes, é, em primeiro lugar, estimular os alunos para que aprendam História e, com isso, consigam desconstruir ou desnaturalizar conceitos. A preocupação é ensinar o conteúdo básico para depois romper, formar valores e abrir ventanas ou portas, oferecendo um discurso diferente - se não oposto - do veiculado nos meios de comunicação de massa.

É um significado bastante realista para um trabalho que tem por foco as utopias. Entretanto, este resultado concorda com o conceito de utopia aqui adotado, ao se vincular com a crítica ao presente e o desejo de aperfeiçoá-lo. Portanto, ensinar História, de forma democrática, transmitindo valores (preservação) e estimulando a crítica (rebeldia, ruptura) é o papel do professor. Isso combina, em parte, com as projeções que os docentes faziam antes de começar a profissão. Unânime era a vontade de fazer diferente, de romper: com a transmissão factual de nomes e datas, com posturas autoritárias, com o ensino sem densidade acadêmica e ausente de debates. $\mathrm{O}$ ingênuo desejo de transformar o mundo exclusivamente pela educação não predominou entre esses professores.

Quando refletiram sobre a influência que possuíam no futuro dos jovens e na melhoria da vida, alguns sentiram certa insegurança, mas, de forma geral, confiavam que podiam colaborar. As ressalvas, geralmente, dirigiam-se ao sistema escolar e às condições de trabalho, comentadas anteriormente. Ou seja, a dúvida não estava no potencial da Educação ou do conhecimento histórico, mas nas condições oferecidas para que os jovens aprendessem.

Percebem-se também as demonstrações de alegria e afeto quando dizem por que continuam a ser professores: "Ah, porque en gosto de ser professora" é a resposta padrão. Divertem-se, aprendem, são desafiados, recebem carinho e reconhecimento. Não importa se não são unanimidade, ou se alguns jovens, por vezes, não "abrirão as portas" nem olharão pelas "ventanas" oferecidas, pois eles sentem que cumpriram com a responsabilidade do professor - e o "fizeram bem feito".

Por isso, à exceção de Fidelio, nenhum se arrepende da escolha ou deseja abandonar a profissão. No máximo, gostariam de lecionar - também - no Ensino Superior. Como planos futuros, destacam-se três recorrências que parecem fundamentais para o tema. Primeiro, o desejo de melhorar como professores nos aspectos didáticos e pedagógicos. Segundo, a vontade de avançar nos estudos, a fim de conquistar autonomia e abertura de outros campos de docência. Terceiro, a busca de caminhos para evitar o desgaste da profissão - seja pela mudança de 
escolas (Josep), pela redução da carga horária (Mercedes), pela pós-graduação (Cândido e Lola) ou pela eliminação de tarefas (Fidelio). O interesse é que são todas iniciativas individuais. Não entraram na lista mudanças como a ampliação da "hora-atividade" ou a existência de espaços de estudo (para o professor) nas próprias escolas. Seria falta de confiança no Estado para a concretização da utopia político-educacional?

Por outro lado, as utopias declaradas são, de maneira geral, coletivas. Poucos professores enunciaram utopias que dissessem respeito apenas a sua vida pessoal. Talvez a pergunta tenha soado capciosa, pois todos afirmaram ser difícil mapear o grau de influência sobre os jovens, porque não podem acompanhá-los no médio ou longo prazo necessário. Eles concordam que nem todos aproveitarão as aulas na mesma intensidade.

Talvez neste sentido a utopia político-educacional de Ana, Fidelio, Regina, Mercedes, Agnês, Josep, Cândido e Lola seja a esperança de que seus esforços não serão em vão: que as escolas públicas sejam boas e que os alunos adquiram sentido e criticidade com elas. E que o mundo seja mais justo, tarefa para a qual suas aulas contribuem - em alguma medida algo difícil de avaliar.

A abordagem comparativa demonstrou que, entre os oito participantes, há coincidências nos significados atribuídos às utopias político-educacionais. Eles expressaram algumas utopias que carregavam - em alguns casos, desde que decidiram se tornar professores. Foram unânimes ao revelar dois importantes obstáculos: primeiro, a formação inicial (e, por vezes, também a continuada), insuficiente para que aprendessem a concretizar seus projetos. Segundo, as condições de trabalho, que não possibilitam a plena execução de seu papel profissional. E é com base nessa crítica que se recolhem significados preciosos para compreender a importância da projeção de utopias político-educacionais na constituição da profissionalidade docente.

Para Lüdke e Boing (2004), a precarização do trabalho docente passa pelo baixo salário e pela desvalorização social do ensino. Os autores acreditam que as relações de mercado atingem profundamente a profissionalidade docente. Profissões como a da docência apresentam fortes características pessoais, segundo Gorz (2005). Para ele, quanto melhores forem as qualidades pessoais dispostas no trabalho, mais difícil é mensurar seu valor, pois, "no limite, a competência pessoal transcende a norma das atribuições profissionais e aparece como uma arte cujo prestador é um virtuose" (GORZ, 2005, p. 33). Ensinar História tendo em vista a emancipação humana pode se tornar um peso gigantesco, e, quando os resultados desejados não aparecem, a frustração ganha espaço. Assim, as utopias político-educacionais, de motivadoras, tornar-se-iam fonte de paralisação. 
Para Dubois (2009), é exatamente este o grande problema das utopias pedagógicas: ignorar a diversidade de opiniões e as possíveis resistências à imposição de um modelo único de vida e de futuro. Entre os professores entrevistados, porém, havia clareza dessa tensão (à exceção, talvez, de Fidelio e de Ana). Concentrar-se em ensinar história da melhor forma possível e aperfeiçoar-se para ser um profissional cada vez melhor foram as saídas encontradas pelo grupo até o momento. Desistir estava fora de questão. Quiçá comungassem, com Arendt (2009), certa perspectiva sobre o educador, que repousa na "responsabilidade sobre o mundo", isto é, em apresentar aos jovens o que as gerações passadas construíram e permitir que criem seus próprios futuros.

\section{Referências}

ALMEIDA NETO, A. S. Dimensão utópica nas representações sobre o ensino de história: memórias de professores. 2002. 310 f. Tese (Doutorado em Educação) Universidade de São Paulo, São Paulo, 2002.

ARENDT, H. A crise na educação. In: ARENDT, H. Entre o passado e o futuro. Tradução de Mauro W. Barbosa. 6. ed. São Paulo: Perspectiva, 2009. p. 21-56.

BACZKO, B. Utopia. In: Enciclopédia Einaudi. Lisboa: Anthropos Homem, 1989. v. 5. p. 67-101.

BOBBIO, N.; MATEUCCI, N.; PASQUINO, G. Dicionário de Política. Brasília: Editora UNB, 1998.

BOTO, C. Na Revolução Francesa, os princípios democráticos da escola pública, laica e gratuita: o relatório de Condorcet. Educação \& Sociedade, Campinas, v. 24, n. 84, p. 735762 , set. 2003.

CABANAS, J. Epistemologia de la Pedagogía Comparada. Educar: Revista del Departament de Pedagogia i de Didàctica, Barcelona, n. 3, p. 25-59, 1983.

CAMBI, F. Características da educação moderna. In: CAMBI, F. História da Pedagogia. Tradução de Álvaro Lorencini. São Paulo: Editora Unesp, 1999. p. 195-219.

CANÁRIO, R. A escola e a abordagem comparada. Novas realidades e novos olhares. Sísifo: Revista de Ciências da Educação, Lisboa, n. 1, p. 27-36, set./dez. 2006. Disponível em: <http://sisifo.fpce.ul.pt>. Acesso em: 19 abr. 2012.

CHAUÍ, M. Notas sobre utopia. Ciência e Cultura, São Paulo, v. 60, p. 7-12, jul. 2008. Disponível em: <http://cienciaecultura.bvs.br/pdf/cic/v60nspe1/a0360ns1.pdf>. Acesso em: 23 fev. 2012.

COLOMBO, A. La nuova linea dell'utopia. Revista Morus: Utopia e Renascimento, Campinas, n. 6, p. 55-59, 2009.

DELORS, J. et al. Educação: um tesouro a descobrir. Relatório para a Unesco da Comissão Internacional sobre Educação para o século XXI. Tradução de José Carlos Eufrázio. São Paulo: Cortez, 1998. 
DUBOIS, C.-G. Problemas da utopia. Tradução de Ana C. R. Ribeiro. Campinas: Unicamp, IEL, Setor de Publicações, 2009. (Coleção Work in Progress).

FONSECA, S. Ser professor no Brasil: história oral de vida. São Paulo: Papirus, 1997.

FUNES, A.; GINGINS, M.; MORENO, T. Ilusiones y mitos: el lugar del maestro de sociales. In: ESTEPA, J.; DE LA CALLE, M.; SÁNCHEZ, M. (eds.). Nuevos horizontes en la formación del profesorado de Ciencias Sociales. Palencia: Libros Activos / Asociación Universitaria de Profesores de Didáctica de las Ciencias Sociales, 2000. p. 315-324.

FURTER, P. A dialética da esperança: uma interpretação do pensamento utópico de Ernest Bloch. Rio de Janeiro: Paz e Terra, 1974.

GIROUX, H. Os professores como intelectuais. Porto Alegre: Artes Médicas, 1997.

GORZ, A. O imaterial: conhecimento, valor e capital. Tradução de Celso Azzan Jr. São Paulo: Annablume, 2005.

GUIMERÀ, C. Práctica docente y pensamiento del profesor de Historia de Secundaria. 1991. 604 f. Tese (Doutorado) - Departamento de Colegio Universitario de Lleida, Universidad de Barcelona, Barcelona, 1991.

LÜDKE, M.; BOING, L. A. Os caminhos da profissão e da profissionalidade docentes. Educação \& Sociedade, Campinas, v. 25, n. 89, p. 1159-1180, set./dez. 2004.

PACIEVITCH, C.; DE ROSSI, V. L. S. Utopias político-educacionais na literatura acadêmica sobre formação de professores de História no Brasil. In: ENCONTRO NACIONAL PERSPECTIVAS DO ENSINO DE HISTÓRIA, 8., 2012, Campinas. Anais... Campinas: Faculdade de Educação, 2012. p. 1-12. CD-ROM.

PAGÈS, J. Enseñar a enseñar a participar. In: ALBA, N.; GARCÍA, F.; SANTISTEBAN, A. (eds.). Educar para la participación ciudadana en la enseñanza de las ciencias sociales. Sevilla: Díada, 2012. p. 199-209.

PEREYRA, M. La comparación, una empresa razonada de análisis. Por otros usos de la comparación. Revista de Educación: los usos de la comparación en Ciencias Sociales y en Educación, Madrid, número extraordinario, p. 27-76, 1990.

PIOZZI, P. Utopias revolucionárias e educação pública: rumos para uma nova "cidade ética”. Educação \& Sociedade, Campinas, v. 28, n. 100 - Especial, p. 715-735, out. 2007. Disponível em: <www.scielo.br/pdf/es/v28n100/a0528100.pdf>. Acesso em: 23 fev. 2102.

QUARTA, C. Livelli del pensiero utopico: antropologia, storia, letteratura. Revista Morus: Utopia e Renascimento, Campinas, n. 6, p. 229-243, 2009.

ROUSSEFF, D. PT na presidência da República: dez anos de avanços. Disponível em: $<$ http://www.pt.org.br/artigos/view/artigo_pt_na_presidencia_da_republica_dez_anos_ de_avancos_por_dilma_roussef $>$. Acesso em: 03 jan. 2013.

SHIROMA, E.; EVANGELISTA, O. A colonização da utopia nos discursos sobre profissionalização docente. Perspectiva, Florianópolis, v. 22, n. 02, p. 525-545, jul./dez. 2004.

SILVA, O. Instituto Talentos convida para o XIII Evento Inovar \& Empreender 2012. Instituto Talentos. Disponível em: <http://www.institutotalentos.com.br/hs4.php>. Acesso em: 20 nov. 2012. 
SOARES, O. P. A atividade de ensino de História: processo de formação de professores e alunos. Araraquara: Junqueira \& Marin, 2008.

SOARES, R. D. A pedagogia de Gramsci no Brasil. Temas Gramsci. Jul. 2004. Disponível em: <http://www.acessa.com/gramsci/texto_impressao.php?id=168>. Acesso em: 01 out. 2011.

Recebido em 19/02/2013

Aceito em 14/05/2013 